\title{
Determination of Letrozole in Tablet Formulations by Reversed Phase High Performance Liquid Chromatography
}

\author{
Mani Ganesh ${ }^{1,2 \star}$, Krishanan Rajasekar ${ }^{2}$, Margandan \\ Bhagiyalakshmi ${ }^{1}$, Mari Vinoba ${ }^{3}$, Kavimani Saktimanigandan ${ }^{4}$, \\ Hyun Tae Jang ${ }^{1}$ \\ ${ }^{1}$ Department of Chemical Engineering, Hanseo University, Season 360-706, South Korea, ${ }^{2}$ Department of \\ Nanotechnology, Biotechnology Centre, Anna University Coimbatore, Jothipuram, Coimbatore 641-047, India, ${ }^{3}$ Carbon \\ Dioxide Reduction \& Sequestration Research Center, Korea Institute of Energy Research, Deajon, 305-343, Korea, \\ ${ }^{4}$ Alkem Lab Ltd, Taloja-410208, Navi Mumbai, Maharashtra, India
}

\begin{abstract}
Purpose: To develop a simple, rapid, accurate and cost-effective reversed phase high performance liquid chromatography (RP-HPLC) method for letrozole in bulk and in tablets.

Methods: Development of a method for the determination of letrozole, an anti-cancer drug, by RPHPLC was undertaken using a new mobile phase of acetonitrile:water $(50: 50, \mathrm{v} / \mathrm{v})$. The eluent was monitored at $265 \mathrm{~nm}$.

Results: The optimized conditions developed showed a linear response from 160 to $240 \mu \mathrm{g} / \mathrm{mL}$, with a correlation coefficient $\left(R^{2}\right)$ of 0.999 . The limit of detection (LOD) and limit of quantification ( $\left.L O Q\right)$ were 136 and $160 \mu \mathrm{g} / \mathrm{mL}$, respectively. The assay values for the two branded letrozole tablets tested were 99.2 and $100.2 \%$, respectively with \% relative standard deviation (RSD) of 0.781 and 0.568 , respectively. The bench top stability data of the drug in the mobile phase indicate that the drug was stable in the mobile phase for $24 \mathrm{~h}$. Recovery data were good. Placebo study for specificity and interference of common excipients showed that the method was specific and free from interfering substances.

Conclusion: Therefore, the fully validated method developed was sensitive enough to carry out routine analysis of letrozole in tablet formulations with regard to its run time, simplicity of sample preparation and accuracy.
\end{abstract}

Key words: Letrozole, Assay, HPLC, Validation, Tablet formulation. 


\section{INTRODUCTION}

Letrozole (LZ), denoted chemically as 4, 4'[(1H-1,2,4-triazol-1-yl) methylene] bisbenzonitrile (see Figure 1), is a highly potent and selective third generation aromatase inhibitor (Al) used for the treatment of hormone-sensitive breast cancer in postmenopausal women [1]. It works by effectively blocking the synthesis of estrogen, a causative agent for cancer [2,3]. LZ is more potent than other $\mathrm{Al}$ and it inhibits the aromatase enzyme in peripheral tissues completely [4-7].

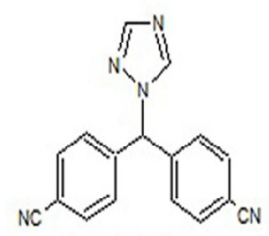

Fig. 1: Structure of letrozole

Several analytical methods have been described for the determination of letrozole in plasma and urine by LC-MS/MS [8], HPLC with fluorescence detection using fully automated liquid-solid extraction [9], micellar electrokinetic chromatography [10], as well as in pharmaceutical formulations by UV method [11]. Nita et al [12] recently described a method based on HPLC with UV detection but even in this method, the analyte was eluted at about the ninth minute which leads to a longer runtime for a single sample. Furthermore, the triple solvent system used was not suitable for routine analysis of the drug in pharmaceuticals. Here in this report, we describe a simple, fully validated HPLC method with UV detection, and which has an advantage in terms of its run-time, simple solvent system, and non-extractive sample preparation.

\section{EXPERIMENTAL}

\section{Chemicals and reagents}

Letrozole (LZ) reference standard was obtained from Sigma Laboratories,
Bangalore, India. Branded letrozole products (Fertolet $^{\circledR}$, Cipla Ltd, India, and Letzol ${ }^{\circledR}$, Vhb Life Sciences, India) both containing LZ (2.5 $\mathrm{mg} /$ tablet) were purchased from a local pharmacy. Acetonitrile (HPLC grade) was purchased from J.T. Baker, New Jersey, USA while Milli-Q was obtained from Millipore Water System, Billerica, USA. All other chemicals and reagents were purchased from Rankem India Ltd, Bombay, India and used as such.

\section{Chromatographic conditions}

Analysis was performed with a Shimadzu LC10 AT VP system equipped with a SPD10UV-visible detector and a Rheodyne-7125 injector with $20 \mu \mathrm{l}$ sample loop. Letrozole was separated on a Phenomenex ODS analytical column $(250 \times 4.6 \mathrm{~mm}, 5 \mu \mathrm{m})$ under reversed phase condition. The mobile phase was a mixture of acetonitrile and water in 50:50 (v/v) ratio with $1.0 \mathrm{~mL} / \mathrm{min}$ flow rate and the analyte was monitored at a wavelength of $265 \mathrm{~nm}$.

\section{Calibration curve}

Calibration plots were constructed using least-squares method by plotting peak area response of appropriate working standards of LZ in mobile phase against concentration.

\section{Limits of detection (LOD) and quantification (LOQ)}

LOD is a measure of the sensitivity of the method of the method developed. It is usually regarded as the amount for which the signalto-noise ratio (SNR) is $S / N>3$. In addition, the LOQ lowest concentration of an analyte that can be quantified with acceptable precision and accuracy,

\section{Stability}

Bench top stability was carried out to assess the stability of LZ standard in mobile phase for $24 \mathrm{~h}$. For long-term stability studies the same standard was conditioned at $4 \stackrel{\circ}{ } \mathrm{C}$ for 
one week, increased to room temperature and then injected into the HPLC system.

\section{Assay sample preparation}

A uniform mixture of tablet powder was obtained by powdering and mixing twenty tablets. From this powder mixture, an amount of the tablet powder equivalent to 50 mg LZ was transferred to a $50 \mathrm{~mL}$ standard flask. A small amount of mobile phase was added and sonicated to dissolve. The volume was made up with mobile phase, filtered with a $0.45 \mu$ syringe filter and $5 \mathrm{~mL}$ of this solution was diluted to $25 \mathrm{~mL}$ with mobile phase to obtain a concentration of $200 \mu \mathrm{g} / \mathrm{mL}$. From this solution, $20 \mu \mathrm{L}$ was injected into the HPLC system.

\section{Ruggedness}

Ruggedness was established by determining LZ in the tablet formulation using two different chromatographic systems (Shimadzu, LC10ADVP isocratic pump with SPD-10 UV/Visible detector) and two different analysts.

\section{RESULTS}

\section{Chromatography}

Symmetrical peaks were observed for $L Z$ at a retention time (RT) of $4.5 \mathrm{~min}$. Typical chromatograms of the blank, LZ standard and tablet formulation are illustrated in Figs 2(a), 2(b) and 3(a), respectively. The chromatograms showed less tailing when compared to earlier reported methods [12].

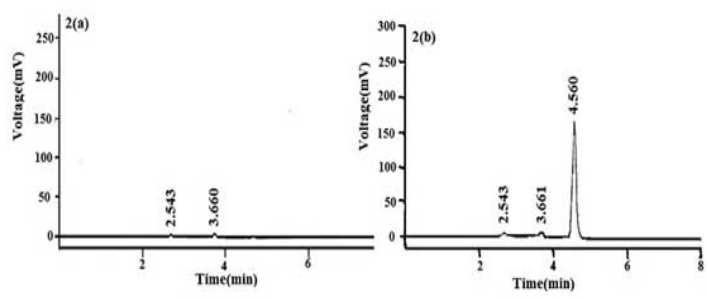

Fig 2: Chromatograms of blank (2a) and standard (reference) letrozole (2b)

\section{Linearity}

The linearity of the peak area with respect to the concentration of the standard, examined under optimal HPLC/UV conditions, is described by the regression equation, $\mathrm{y}=$ $5.5255 \mathrm{c}-0.235$, where ' $c$ ' is the concentration $(\mu \mathrm{g} / \mathrm{mL})$. The curve was observed to be linear from $160-240 \mu \mathrm{g} / \mathrm{mL}$ with linear regression of 0.999 .

\section{Method validation}

Method validation was performed by following the International Conference on Harmonisation $\mathrm{ICH}$ and United States Pharmacopoeia (USP) guideline for analytical method validation $[13,14]$.

\section{Intra-day and inter-day precision and accuracy}

For intra-day precision evaluation, a standard solution of fixed concentration was injected at various time intervals and RSD was $0.83 \%$ (limit RSD < 2.0\%). In addition, the day-today (inter-day) precision was studied by injecting the same concentration of standard solution on consecutive days and the RSD was 0.78 (limit RSD <2.0\%). The results are provided in Table 1. The accuracy of the method was assessed by recovery of LZ in the dosage formulation at three concentration levels $(80,100$ and $120 \%$ with reference to label claim of tablet. Recoveries ranged from 98.6 to $99.2 \%$ (Table 1 ).

\section{Specificity}

Placebo, blank and sample run were carried out to determine the specificity of the chromatographic method developed for $L Z$. Comparison of Figs 2 and 3 indicate that the placebo (which had had the excipients of the tablet formulation but not the drug) did not show any peak, indicating that there was no interference with or suppression of the peak at the retention time of $L Z$ due to the solvent used o commonly used tablet excipients. 
Ganesh et al

Table 1: Linearity, precision and accuracy data

\begin{tabular}{|c|c|c|c|c|c|}
\hline \multirow{2}{*}{\multicolumn{2}{|c|}{$\begin{array}{c}\text { Linearity } \\
\text { Concentration } \\
(\mu g / m L) \\
\end{array}$}} & \multicolumn{2}{|c|}{ Precision of method } & \multicolumn{2}{|c|}{ Accuracy } \\
\hline & & Inter-day* & $\begin{array}{c}\text { Intraday }^{*} \\
\text { (3 days) }\end{array}$ & Spike level & $\%$ Recovery ${ }^{* *}$ \\
\hline \multicolumn{6}{|c|}{160} \\
\hline \multicolumn{2}{|c|}{180} & 083 & 078 & $80 \%$ & 99.20 \\
\hline \multicolumn{2}{|c|}{200} & 0.00 & 0.10 & $100 \%$ & 98.57 \\
\hline \multicolumn{2}{|c|}{220} & & & $120 \%$ & 98.95 \\
\hline \multicolumn{2}{|c|}{240} & & & & \\
\hline $\mathrm{R}^{2}$ & 0.999 & & & & \\
\hline Intercept & -0.235 & & & & \\
\hline Slope & 5.525 & & & & \\
\hline
\end{tabular}

\section{Ruggedness}
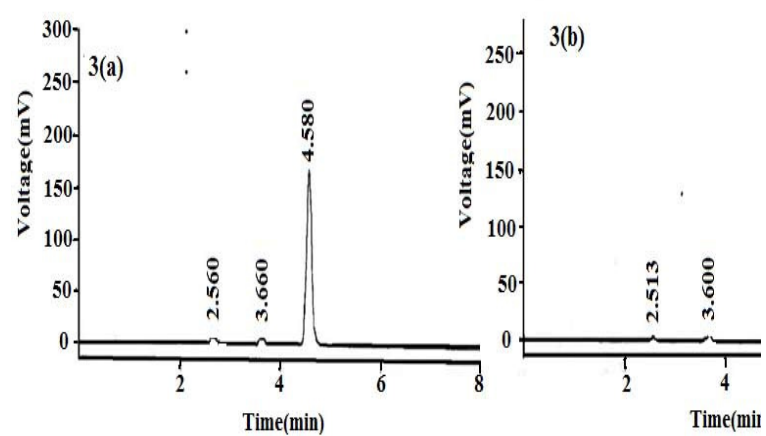

Fig 3: Chromatograms of $L Z$ tablet formulation (3a) and placebo (3b) showing absence of peak at the retention time of LZ)

\section{Limits of detection and quantitation}

The limit of detection (LOD) for letrozole was $136 \mu \mathrm{g} / \mathrm{mL} \quad(\mathrm{S} / \mathrm{N}>\quad 3)$ while the limit of quantitation (LOQ) for the drug was 160 $\mu \mathrm{g} / \mathrm{mL}(\mathrm{S} / \mathrm{N}>10)$.

\section{Stability}

The drug was stable up to $24 \mathrm{~h}$ at room temperature, and stable up to one week under refrigerated condition $\left(4^{\circ} \mathrm{C}\right)$. From the results shown in Table 2, it was observed that the assay values after $24 \mathrm{~h}$ and 7 days were 99.6 and $100.9 \%$, respectively, which indicates that LZ was stable for up to one week as it did not show any degradation.
The RSD for analyst and inter-system variations were $0.75-0.80 \%$ (limit $<2.0 \%$ ) and $0.86-1.01 \%$ (limit $<2.0 \%$ ), respectively. This indicates that the method was rugged (Table 2 ).

\section{Application of the developed method to tablets}

The results obtained when the developed method was used for the determination of $L Z$ in two different commercial tablet formulations ( $\mathrm{F}-1$ and $\mathrm{F}-1$ ) are shown in Table 3. The actual assay results were very close to the labelled strength claim and RSD (\%) values were low, thus confirming that the developed method is suitable for routine determination of these components in their pharmaceutical preparation.

\section{DISCUSSION}

Reversed phase high performance liquid chromatography (RP-HPLC) method is widely used in pharmaceutical industries for routine quality control testing for analyte of interest. In this study, we attempted to develop a new method for $L Z$ assay in tablets that is more suitable than other HPLC methods in terms of time of analysis, tailing, cost and mobile phase. Our investigation focused on the development of a simple, cost effective fully 
Table 2: Results of ruggedness and stability

\begin{tabular}{|c|c|c|c|c|c|c|c|c|}
\hline \multicolumn{4}{|c|}{ Stability } & \multirow{3}{*}{$\begin{array}{l}\text { Deviation } \\
\text { from initial } \\
\text { assay }\end{array}$} & \multicolumn{4}{|c|}{ Ruggedness } \\
\hline \multirow{2}{*}{$\begin{array}{l}\text { Initial } \\
\text { assay }\end{array}$} & \multirow{2}{*}{$1^{\text {st }}$ day } & \multirow{2}{*}{$3^{\text {rd day }}$} & \multirow{2}{*}{$7^{\text {th }}$ day } & & \multicolumn{2}{|c|}{ Analyst $^{\star}$} & \multicolumn{2}{|c|}{ System ${ }^{\star}$} \\
\hline & & & & & 1 & 2 & 1 & 2 \\
\hline $99.5 \%$ & 99.57 & $99.6 \%$ & $100.9 \%$ & 0.6 to $1.4 \%$ & $100.6 \%$ & $99.9 \%$ & $100.0 \%$ & $99.7 \%$ \\
\hline \multicolumn{4}{|c|}{ \%RSD (limit: $\leq 2.0 \%$ ) } & & 0.75 & 0.8 & 0.86 & 1.01 \\
\hline
\end{tabular}

${ }^{*}$ where $n=6 ; R S D=$ relative standard deviation

Table 3: Comparison of tablet labelled strength claim with actual assay data $(n=6)$

\begin{tabular}{ccccc}
\hline Formulation & $\begin{array}{c}\text { Labelled strength } \\
\mathbf{m g} / \mathbf{t a b}\end{array}$ & $\begin{array}{c}\text { Assay* } \\
\mathbf{m g} / \mathbf{t a b}\end{array}$ & $\begin{array}{c}\text { Assay }^{*} \\
(\%)\end{array}$ & \% RSD* \\
\hline F-1 & 2.5 & 2.48 & 99.2 & 0.781 \\
F-2 & 2.5 & 2.51 & 100.2 & 0.568 \\
\hline
\end{tabular}

validated method of analysis for $L Z$ with a short runtime and good peak symmetry.

To optimize the method, various mobile phase compositions were tried in preliminary tests. The mobile phase containing acetonitrile and water in a 50:50 ratio was found to be the suitable mobile phase for achieving the goal of interest. The selected mobile phase gave sharp and baseline resolute peak for the analyte, $L Z$, at $265 \mathrm{~nm}$. The method developed gave a good linear response with a correlation coefficient 0.999 and it was fully validated as per $\mathrm{ICH}$ guidelines for parameters linearity such as LOD, LOQ, stability precision, accuracy and ruggedness with good and reliable results in accordance with the guidelines for acceptance limit.

\section{CONCLUSION}

Letrozole was quantified successfully in bulk and tablet formulations by the simple HPLC method that was developed. Many previously reported HPLC methods are less sensitive, exhibited longer run-time and more tailing in the analyte peak, and were only partially validated. The method developed in our work has overcome all these inadequacies and therefore should meet the requirements of the pharmaceutical industries for short runtime, less tailing, cost-effective solvent, simple sample preparation and full validation. Thus this method would be suitable for routine quality control monitoring of letrozole in tablet formulations.

\section{REFERENCES}

1. Lamb HM, Adkins JC. Letrozole. A review of its use in postmenopausal women with advanced breast cancer. Drugs 1998; 56: 1125-1140.

2. Bhatnagar AS, Hausler A, Schieweck K, Lang M, Bowman $R$. Highly selective inhibition of estrogen biosynthesis by CGS 20267, a new non-steroidal aromatase inhibitor J.Steroid. Biochem. Mol Biol. 1990; 37: 1021-1027.

3. Bhatnagar AS, Batzl C, Hausler A, Schieweck K, Lang M, Trunet PF. Pharmacology of nonsteroidal aromatase inhibitors: In: Pasqualini $J R$, Katzenellenbogen BS (eds) Hormonedependent cancer. Marcel Dekker, New York, 1996; $p 155$.

4. Miller WR. Biology of aromatase inhibitors: pharmacology/endocrinology within the breast Endocr Rela Cancer. 1999; 6: 187-195.

5. Lu $Q$, Liu $Y$, Long BJ, Grigoryev D, Gimbel $M$, Brodie $A$. The effect of combining aromatase inhibitors with antiestrogens on tumor growth in a nude mouse model for breast cancer Breast Cancer Rel Treat. 1999; 57: 183-192. 
6. Geisler J, Haynes B, Anker G, Dowsett M, Lønning $P E$. Influence of Letrozole and Anastrozole on Total Body Aromatization and Plasma Estrogen Levels in Postmenopausal Breast Cancer Patients Evaluated in a Randomized, Cross-Over Study. J Clin Oncol. 2002; 20: 751-757.

7. Dixon JM, Renshaw L, Young O, Murray J, Macaskill EJ, McHugh M, Folkerd E, Cameron $D$, Dowsett M. Letrozole suppress plasma oestradiol(E2) levels more completely in postmenopausal women with breast cancer [abstract] .J Clin Oncol. 2006; 24(Suppl 18): 552.

8. Zhang $Y$, Ackerland $C$, Khadang A, Aufman $D$. http://www.aapsj.org / abstracts / AM_2006/AAPS 2006-000433.pdf. Accessed 26 February 2010

9. Marfil F, Pineau V, Sioufi A, Godbillon J. Highperformance liquid chromatography of the aromatase inhibitor, and it's metabolite in biological fluids with automated liquid-liquid extraction and fluorescence detection $J$ Chromatogram B. 1996; 683: 251-258.

10. Rodr'iguez FJ, Contento SAM, Villase nor LMJ, Mũ̃noz FL. Micellar electrokinetic chromato- graphic method for the determination of letrozole, citalopram and their metabolites in human urine. J Chromatogra A. 2008; 1185: 281-290.

11. Ganesh M, Kamalakannan K., Rahul P, Satish U, Anand S, Sivakumar T, Swastika. A validated UV Spectrophotometric method for the determination of Letrozole in bulk and solid dosage form. Rasayan J Chem. 2008; 1: 5558.

12. Nita M, Pal TK, Ghosal SK, Development and validation of RP-HPLC method to determine letrozole in different pharmaceutical formulations and its application to studies of drug release from nanoparticles. Acta Polo Pharmaceutican Drug Resear 2009; 661: 1117.

13. Methodology. ICH Harmonised Tripartite Guideline "Validation of analytical procedures" Having reached Step 4 of the $\mathrm{ICH}$ Process. $\mathrm{ICH}$ Steering Committee Meeting, 6 November 2005.

14. USP 30. The United States Pharmacopoeia, 29th Edn; United States, Pharmacopeial Convention.:Rockville. 2007; pp 680-683. 